\title{
Journal of Judicial Review
}

\section{Peran PPAT Selaku Pengguna Layanan Hak Tanggungan Terintegrasi Secara Elektronik}

\author{
Zidna Aufima* \\ Fakultas Hukum, Universitas Airlangga, Indonesia \\ *Corresponding email: zidna.aufima-2016@fh.unair.ac.id
}

\begin{tabular}{|c|c|}
\hline Info Artikel & Abstract \\
\hline \multirow[t]{2}{*}{$\begin{array}{l}\text { Masuk: 01 Okt. } 2020 \\
\text { Direvisi: 01 Des. } 2020 \\
\text { Disetujui: } 03 \text { Des. } 2020 \\
\text { Keywords: } \\
\text { Land Deed Official; User of } \\
\text { Integrated Encrumbrances } \\
\text { Rights Service Electronically; } \\
\text { Land Office }\end{array}$} & $\begin{array}{l}\text { Since july 8th, 2020, the implementation of integrated encrumbrances rights service } \\
\text { electronically must be implemented nationally by all land offices in Indonesia. This } \\
\text { services that are carried out electronically are carried out to realize ease service to } \\
\text { public. Land Deed Official has important role in integrated encrumbrances rights } \\
\text { service electronically. By using statute approach and conceptual approach. the result of } \\
\text { study showed that Land Deed Official's role as user of integrated encrumbrances rights } \\
\text { service electronically after release Permen ATR/BPN Number } 5 \text { of } 2020 \text { is start from } \\
\text { create credit agreement, checking land certificate electronically before create deed of } \\
\text { granting encrumbrances rights, create deed of granting encrumbrances rights until } \\
\text { uploading deed ofgranting encrumbrances rights to locallandoffice through Land Deed } \\
\text { Official Partner Application on https:/mitra.atrbpn.goid. Then, Land Deed Official } \\
\text { will submit copy of deed of granting encrumbrances rights to Debtor and Creditor. } \\
\text { Meanwhile, original of deed of granting encrumbrances rights is kept by Land Deed } \\
\text { Official. }\end{array}$ \\
\hline & Abstrak \\
\hline $\begin{array}{l}\text { Kata kunci: } \\
\text { PPAT; Hak Tanggungan } \\
\text { Terintegrasi Secara } \\
\text { Elektronik; Kantor } \\
\text { Pertanahan }\end{array}$ & $\begin{array}{l}\text { Sejak } 8 \text { Juli 2020, pelaksanaan Pelayanan Hak Tanggungan Terintegrasi } \\
\text { Secara Elektronik wajib diterapkan secara nasional oleh seluruh Kantor } \\
\text { Pertanahan di Indonesia. Pelayanan ini bertujuan untuk mewujudkan } \\
\text { kemudahan pelayanan HT-el kepada masyarakat. PPAT memiliki peran } \\
\text { penting dalam layanan hak tanggungan terintegrasi secara elektronik. } \\
\text { Metode yang digunakan adalah statute approach dan conceptual } \\
\text { approach. Hasil penelitian ini dapat diketahui bahwa Peran PPAT selaku } \\
\text { pengguna layanan hak tanggungan terintegrasi secara elektronik setelah } \\
\text { diterbitkannya Permen ATR/BPN Nomor } 5 \text { Tahun } 2020 \text { adalah mulai dari } \\
\text { pembuatan perjanjian kredit, pengecekan sertifikat tanah secara } \\
\text { elektronik sebelum membuat Akta Pemberian Hak Tanggungan, } \\
\text { Pembuatan Akta Pemberian Hak Tanggungan sampai mengupload Akta } \\
\text { Pemberian Hak Tanggungan beserta data pendukungnya kepada Kantor } \\
\text { Pertanahan setempat melalui Aplikasi Mitra Kerja PPAT pada } \\
\text { https://mitra.atrbpn.go.id. Kemudian, PPAT akan menyerahkan salinan } \\
\text { minuta Akta Pemberian Hak Tanggungan kepada debitor dan kreditor. } \\
\text { Sementara, Akta Pemberian Hak Tanggungan yang asli disimpan oleh } \\
\text { PPAT. }\end{array}$ \\
\hline
\end{tabular}

Copyright ${ }^{\circ} 2020$ by Author(s)

This work is licensed under a Creative Commons Attribution-Non Commercial-Share Alike 4.0 International License. 


\section{A. PENDAHULUAN}

Tanah merupakan suatu faktor yang sangat penting dalam kehidupan masyarakat (Antari, Windari \& Mangku, 2020), terlebih-lebih di lingkungan myarakat Indonesia yang sebagian besar penduduknya menggantungkan kehidupan dari tanah (Hajati, Winarsi, Sekarmadji \& Moechthar, 2017), karena tanah menjadi kebutuhan primer, sekunder maupun tersier (Budjang, 2019). Tanah selain sebagai tempat hidup kita juga dapat digunakan sebagai obyek jaminan untuk mendapatkan dana dalam bekerja untuk memenuni kebutuhan hidup (Permatasari, Adjie, \& Djanggih, 2018; Riardo, 2019). Lembaga jaminan tanah yang mempunyai kemampuan memberikan kepastian hukum yang kuat dan melindungi baik kreditor maupun debitur yaitu "Hak Tanggungan". Hak Tanggungan adalah hak jaminan atas tanah guna pelunasan utang yang kedudukan krediturnya diutamakan daripada kreditur lain. Kreditor Hak Tanggungan merupakan kreditor preference yaitu kreditor yang didahulukan dalam mendapatkan pelunasan utang dan berhak mengeksekusi secara langsung dengan lembaga parate eksekusi (Jayanti, \& Darmawan, 2018). "Sehingga apabila debitur cidera janji, kreditur sebagai pemegang Hak Tanggungan dapat menjual obyek Hak Tanggungan melalui penjualan dimuka umum atau pelelangan" (Dewi \& Novana, 2020).

Layanan hak tanggungan elektronik sebenarnya sudah dimulai sejak diberlakukannya Permen ATR/BPN Nomor 7 Tahun 2019 tentang perubahan kedua atas Permen ATR/BPN Nomor 3 Tahun 1997 tentang Ketentuan Pelaksanaan PP Nomor 24 Tahun 1997, serta Permen ATR/BPN Nomor 9 Tahun 2019 tentang Pelayanan Hak Tanggungan Terintegrasi secara Elektronik. Dalam Permen tersebut antara lain mengatur Akta PPAT yang disampaikan pada Kantor Pertanahan setempat berupa dokumen elektronik melalui sistem elektronik. Dengan terbitnya Permen ATR/BPN Nomor 5 Tahun 2020 tentang Pelayanan Hak Tanggungan Terintegrasi Secara Elektronik, maka Permen ATR/BPN Nomor 9 Tahun 2019 tentang Pelayanan Hak Tanggungan Terintegrasi Secara Elektronik dicabut. Sejak 8 Juli 2020, pelaksanaan Pelayanan Hak Tanggungan Terintegrasi Secara Elektronik wajib diterapkan secara nasional oleh seluruh Kantor Pertanahan di Indonesia. maka ketentuan Pasal 10 ayat (3) UU HT tidak bisa dilaksanakan. Hal ini diatur dalam Pasal 33 Permen ATR/BPN No. 5 Tahun 2020 Tentang Pelayanan Hak Tanggungan Terintegrasi Secara Elekronik yang menyatakan: "Kantor Pertanahan wajib melaksanakan pelayanan hak tanggungan secara elektronik paling lambat 3 (tiga) bulan sejak berlakunya Peraturan Menteri ini" dan "Setelah jangka waktu 3 (tiga) bulan sebagaimana dimaksud pada ayat (l) pelayanan Hak Tanggungan hanya dapat dilakukan secara elektronik".

Menurut Permen ATR/BPN No. 5 Tahun 2020 Tentang Pelayanan Hak Tanggungan Terintegrasi Secara Elekronik, jenis layanan Hak Tanggungan yang dapat diajukan melalui Sistem Hak Tanggungan Elektronik meliputi Pendaftaran Hak Tanggungan, Peralihan Hak Tanggungan, Perubahan Nama Kreditor, 
Penghapusan Hak Tanggungan, dan Perbaikan Data. Sementara objek Hak Tanggungan yang dapat diproses dengan pelayanan Hak Tanggungan Elektronik merupakan objek Hak Tanggungan sebagaimana diatur dalam Undang-Undang Nomor 4 Tahun 1996 tentang Hak Tanggungan Atas Tanah Beserta Benda-Benda Yang Berkaitan Dengan Tanah (UU HT). Dalam hal pengecekan sertipikat untuk keperluan pembuatan akta oleh PPAT, harus dilakukan secara elektronik dengan berdasarkan Surat Edaran Kepala Badan Pertanahan Nasional Nomor DI.01.01/361100/II/2020 tanggal 17 Februari 2020 perihal pengecekan secara elektronik terhadap bidang tanah, PPAT memiliki kewajiban melakukan pengecekan sertipikat tanah secara elektronik sehingga pengecekan sertipikat tanah secara manual ditutup pada tanggal 30 Juli 2020.

Permasalahan yang diangkat pada penelitian ini adalah: Apa karakteristik jaminan hak tanggungan menurut peraturan perundang-undangan di negara republik indonesia?; dan Apa peran PPAT selaku pengguna layanan hak tanggungan terintegrasi secara elektronik pasca terbitnya Permen ATR/BPN Nomor 5 Tahun 2020?.

\section{B. METODE PENELITIAN}

Penelitian ini merupakan penelitian hukum normatif, yaitu metode dengan pendekatan pengkajian terhadap asas-asas hukum dan sistematika hukum yang ada dalam peraturan perundang-undangan yang berlaku, sehingga penelitian secara normatif ini dapat fokus pada inventarisasi hukum positif. Penelitian ini juga mengunakan pendekatan perundang-undangan (statute approach). Pendekatan perundang-undangan (statute approach) adalah pendekatan dengan menelaah semua peraturan perundang-undangan dan regulasi yang berhubungan satu sama lain dengan permasalahan yang dibahas (Marzuki, 2011).

\section{HASIL DAN PEMBAHASAN}

\section{Karakteristik Jaminan Hak Tanggungan di Indonesia}

Definisi Hak Tanggungan adalah hak jaminan yang dibebankan pada hak atas tanah (Taqiyyah \& Winanti, 2020), berikut atau tidak berikut benda-benda lain yang merupakan satu kesatuan dengan tanah itu, untuk pelunasan utang tertentu yang memberikan kedudukan yang diutamakan kepada kreditur tertentu terhadap kreditur-kreditur lain (Usanti \& Bakarbessy, 2014).

Adapun ciri-ciri hak tanggungan adalah (Usanti \& Bakarbessy, 2014): 1) Droit de preference (Pasal l angka l jo. Pasal 20 ayat (1) UU HT); 2) Droit de suite (Pasal 7 UU HT); 3) Memenuhi asas spesialitas dan asas publisitas. Asas spesialitas yaitu asas yang mewajibkan dalam muatan akta pemberian hak tanggungan harus mencantumkan ketentuanketentuan seperti ditegaskan dalam Pasal 11 UU HT. Sedangkan asas publisitas yaitu asas yang mewajibkan didaftarkannya hak tanggungan pada kantor pertanahan setempat (Pasal 13 UU HT); 4) Mudah dan 
pasti pelaksanaan eksekusinya; dan 5) Objek hak tanggungan tidak masuk dalam boedel kepailitan pemberi hak tanggungan sebelum kreditor pemegang hak tanggungan mengambil pelunasan dari hasil penjualan obyek hak tanggungan (Pasal 21 UU HT).

Sifat-sifat Hak Tanggungan antara lain (Usanti \& Bakarbessy, 2014): 1) Tidak dapat dibagi-bagi (Pasal 2 UU HT) Meskipun sifat hak tanggungan tidak dapat dibagi-bagi, artinya hak tanggungan membenani obyek secara utuh, namun sifat ini tidak berlaku mutlak dengan pengecualian dimungkinkan roya parsial, sepanjang diperjanjikan dalam Akta Pemberian Hak Tanggungan (APHT); dan 2) Bersifat accesoir atau perjanjian ikutan adalah perjanjian jaminan utang atas hak tanggungan tidak berdiri sendiri karena ikut pada perjanjian pokok yaitu perjanjian utang-piutang, apabila perjanjian pokok hapus atau batal, maka otomatis perjanjian accesoir menjadi hapus.

Berdasarkan Pasal 4 UU HT, Obyek Hak Tanggungan antara lain (Usanti \& Bakarbessy, 2014): 1) Hak-hak atas tanah yang dapat dibebani hak tanggungan adalah hak milik, hak guna usaha dan hak guna bangunan; 2) Hak pakai atas tanah Negara yang menurut ketentuan wajib didaftar dan menurut sifatnya dapat dipindahtangankan dapat juga dibebani hak tanggungan; 3) Pembebanan Hak Tanggungan pada Hak Pakai atas tanah Hak Milik akan diatur lebih lanjut dengan Per-aturan Pemerintah; 4) Hak Tanggungan dapat juga dibebankan pada hak atas tanah berikut bangunan, tanaman, dan hasil karya yang telah ada atau akan ada yang merupakan satu kesatuan dengan tanah tersebut, dan yang merupakan milik pemegang hak atas tanah yang pembebanannya dengan tegas dinyatakan di dalam Akta Pemberian Hak Tanggungan; 5) Apabila bangunan, tanaman, dan hasil karya tidak dimiliki oleh pemegang hak atas tanah, pembebanan Hak Tanggungan atas benda-benda tersebut hanya dapat dilakukan dengan penandatanganan serta pada Akta Pemberian Hak Tanggungan yang bersangkutan oleh pemilik atau yang diberi kuasa untuk itu olehnya dengan akta otentik.

Menurut Pasal 12 ayat (1) Undang-Undang Nomor 16 Tahun 1985 tentang Rumah Susun menyatakan Rumah Susun berikut tanah tempat bangunan itu berdiri serta benda lainnya yang merupakan atau kesatuan dengan tanah tersebut dapat dijadikan jaminan utang dengan (Usanti \& Bakarbessy, 2014): 1) Dibebani hipotik, jika tanahnya tanah milik atau hak guna bangunan; 2) Dibebani fidusia, jika tanahnya hak pakai atau tanah Negara, namun dengan keluarnya UU HT maka hak pakai tidak lagi dibebankan dengan fidusia tetapi dengan hak tanggungan (pasal 27 UU HT).

Proses penjaminan Hak Tanggungan ada 3 tahap, yaitu Pertama tahap pemberian Hak Tanggungan yang diawali dengan dibuatnya perjanjian utang atau perjanjian kredit sebagai perjanjian pokok. Kedua, tahap pemberian Hak Tanggungan dengan dibuatnya Akta Pemberian Hak Tanggungan (APHT) oleh dan di hadapan PPAT, yang bentuk dan isinya ditetapkan dengan Permen 
ATR/BPN Nomor 3 Tahun 1996 tentang Bentuk Surat Kuasa Membebankan Hak Tanggungan, Akta Pemberian Hak Tanggungan, Buku Tanah Hak Tanggungan, dan Sertipikat Hak Tanggungan. Di dalam APHT dapat dicantumkan janji oleh para pihak, sebagaimana yang telah ditentukan dalam ketentuan Pasal 11 ayat (2) UU HT. Ketiga, tahap pendaftaran Hak Tanggungan Terintegrasi Secara Elektronik.

Mekanisme Pelayanan Hak Tanggungan Terintegrasi Secara Elektronik diatur dalam Pasal 9 sampai Pasal 23 Peraturan Menteri Agraria dan Tata Ruang/Kepala Badan Pertanahan Nasional Nomor 5 Tahun 2020: Pertama, Kreditor mengajukan permohonan Pelayanan HT-el melalui Sistem HT-el yang disediakan oleh Kementerian. Dalam hal permohonan Pelayanan HT-el berupa pendaftaran Hak Tanggungan atau peralihan Hak Tanggungan, dokumen kelengkapan persyaratan disampaikan oleh PPAT. Dalam hal permohonan Pelayanan HT-el berupa perubahan nama Kreditor, penghapusan Hak Tanggungan, atau perbaikan data, dokumen kelengkapan persyaratan disampaikan oleh Kreditor. Persyaratan permohonan Pelayanan HT-el disampaikan dalam bentuk Dokumen Elektronik. Kedua, PPAT menyampaikan akta dan dokumen kelengkapan persyaratan berupa pendaftaran Hak Tanggungan atau peralihan Hak Tanggungan melalui sistem elektronik mitra kerja yang terintegrasi dengan Sistem HT-el. Penyampaian dokumen dilengkapi dengan Surat Pernyataan mengenai pertanggungjawaban keabsahan dan kebenaran data Dokumen Elektronik yang diajukan. Seluruh dokumen kelengkapan persyaratan tersebut wajib disimpan oleh PPAT.

Ketiga, Permohonan Pelayanan HT-el yang telah diterima oleh Sistem HT-el diberikan tanda bukti pendaftaran permohonan yang diterbitkan oleh sistem HTel. Pelayanan HT-el dikenakan biaya Penerimaan Negara Bukan Pajak. Keempat, Permohonan diproses setelah data permohonan dan biaya Penerimaan Negara Bukan Pajak terkonfirmasi oleh Sistem HT-el. Dalam hal pembayaran biaya Penerimaan Negara Bukan Pajak tidak terkonfirmasi oleh Sistem HT-el, Kreditor dapat melakukan konfirmasi secara langsung ke Kantor Pertanahan atau Layanan Pengaduan. Kelima, Sebelum hasil Pelayanan HT-el diterbitkan, Kepala Kantor Pertanahan atau pejabat yang ditunjuk harus memeriksa kesesuaian dokumen persyaratan dan konsep Sertipikat HT-el. Pemeriksaan kesesuaian dokumen persyaratan dan konsep Sertipikat HT-el dilakukan melalui Sistem HT-el. Dalam hal hasil pemeriksaan terdapat dokumen yang tidak lengkap atau tidak sesuai, diberitahukan kepada Kreditor dan/atau PPAT untuk segera melengkapi berkas. Dokumen persyaratan harus dilengkapi paling lama hari ke 5 (lima) sejak permohonan pelayanan diterima oleh Sistem HT-el. Dalam hal jangka waktu tersebut berakhir dan Kreditor dan/atau PPAT tidak melengkapi berkas, maka permohonan dinyatakan batal. Dalam hal dokumen persyaratan telah sesuai, Kepala Kantor Pertanahan atau pejabat yang ditunjuk memberikan persetujuan atas unggahan dokumen persyaratan dan konsep Sertipikat HT-el. 
Keenam, Dalam hal Kepala Kantor Pertanahan atau pejabat yang ditunjuk tidak melakukan pemeriksaan sampai pada hari ke-7 (tujuh) dan hasil Pelayanan HT-el diterbitkan oleh Sistem HT-el, dianggap memberikan persetujuan dan/atau pengesahan. Kepala Kantor Pertanahan atau pejabat yang ditunjuk bertanggung jawab secara administratif atas hasil Pelayanan HT-el. Ketujuh, Hasil Pelayanan HTel berupa Dokumen Elektronik yang diterbitkan oleh Sistem HT-el, meliputi: Sertipikat HT-el; Catatan Hak Tanggungan pada buku tanah hak atas tanah atau Hak Milik Atas Satuan Rumah Susun; dan Catatan Hak Tanggungan pada Sertipikat Hak Atas Tanah atau Hak Milik Atas Satuan Rumah Susun. Pencatatan Hak Tanggungan pada buku tanah hak atas tanah atau Hak Milik Atas Satuan Rumah Susun dilakukan pada Buku Tanah Elektronik oleh Kepala Kantor Pertanahan atau pejabat yang diberi kewenangan. Pencatatan Hak Tanggungan pada Sertipikat Hak Atas Tanah atau Hak Milik Satuan Rumah Susun dilakukan oleh Kreditor pada Sertipikat Hak Atas Tanah atau Hak Milik Satuan Rumah Susun yang dijaminkan. Catatan tersebut menjadi satu kesatuan dengan Sertipikat Hak Atas Tanah atau Hak Milik Satuan Rumah Susun. Hasil Pelayanan HT-el disampaikan kepada Kreditor melalui Sistem HT-el dan/atau melalui Domisili Elektronik. Kedelapan, Hasil Pelayanan HT-el disahkan dengan Tanda Tangan Elektronik oleh Kepala Kantor Pertanahan atau pejabat yang diberi kewenangan, untuk menjaga keutuhan dan keautentikan Dokumen Elektronik. Tanda Tangan Elektronik dilakukan sesuai dengan ketentuan peraturan perundang-undangan. Penerbitan Sertipikat HT-el dilakukan pada hari ke-7 (tujuh) setelah permohonan Pelayanan HT-el terkonfirmasi Sistem HT-el.

Kesembilan, Pelayanan pendaftaran Hak Tanggungan peringkat kedua dan selanjutnya, diterbitkan Sertipikat HT-el baru dengan nomor yang baru. Pelayanan peralihan Hak Tanggungan, perubahan nama Kreditor, penghapusan Hak Tanggungan sebagian (roya parsial), atau perbaikan data, diterbitkan Sertipikat HT-el baru dengan nomor yang sama dengan sertipikat sebelumnya, yang berisikan data perubahan terakhir. Pelayanan penghapusan Hak Tanggungan keseluruhan (roya penuh), Sertipikat HT-el sebelumnya diberikan tanda khusus yang menyatakan bahwa sertipikat tidak berlaku. Sepuluh, Dalam hal piutang telah lunas, Kreditor segera mendaftarkan penghapusan Hak Tanggungan. Permohonan pelayanan penghapusan Hak Tanggungan diajukan melalui Sistem HT-el. Sebelas, Dalam hal terjadi kesalahan pengisian data dalam permohonan Pelayanan HT-el yang diketahui setelah hasil Pelayanan HT-el diterbitkan, pemegang Sertipikat HT-el dapat mengajukan perbaikan. Permohonan perbaikan Sertipikat HT-el diajukan melalui Sistem HT-el paling lama 30 (tiga puluh) hari sejak tanggal Sertipikat HT-el diterbitkan. Perbaikan Sertipikat HT-el dikenakan biaya penggantian sertipikat. Duabelas, Pelaksanaan Pelayanan HT-el menjadi tanggung jawab Kepala Kantor Pertanahan. Kebenaran materiil dokumen yang menjadi dasar hasil Pelayanan HT-el bukan merupakan tanggung jawab Kantor Pertanahan. 
Dalam hal terdapat dokumen yang dinyatakan palsu dan digunakan sebagai dasar penerbitan Sertipikat HT-el, maka pegawai Kantor Pertanahan tidak dapat dikenai pertanggungjawaban secara hukum. Dokumen yang dinyatakan palsu, sepenuhnya menjadi tanggung jawab pengirim dokumen baik pidana maupun perdata.

Tigabelas, Pemegang Sertipikat HT-el dilarang: mengubah isi, melakukan manipulasi, penciptaan, perubahan, penghilangan, perusakan Informasi Elektronik dan/atau Dokumen Elektronik dengan tujuan agar Informasi Elektronik dan/atau Dokumen Elektronik tersebut dianggap seolah-olah data yang otentik; dan/atau menggandakan, mendistribusikan dan/atau mentransmisikan, memindahkan atau mentransfer, mengakibatkan terbukanya Informasi Elektronik dan/atau Dokumen Elektronik atau salinannya kepada pihak lain yang tidak terkait dalam perbuatan hukum Hak Tanggungan. Pemegang Sertipikat HT-el yang melakukan pelanggaran dikenakan sanksi. Empatbelas, Pengguna Terdaftar dilarang: memalsukan identitas; memberikan username dan/atau password kepada pihak lain yang menyebabkan terbukanya akses informasi; memalsukan dokumen dan/atau memberikan informasi yang tidak benar yang menyebabkan kesalahan hasil Pelayanan HT-el. Terakhir Limabelas, Pemegang Hak Tanggungan dan/atau Pengguna Terdaftar sebagaimana dimaksud dalam Pasal 21 dan Pasal 22 dapat dikenakan: penutupan hak akses sementara atau permanen; pembatalan Sertipikat HT-el; dan/atau dilaporkan kepada aparat penegak hukum. Pembatalan Sertipikat HT-el dilaksanakan sesuai dengan ketentuan peraturan perundang-undangan.

Peran PPAT selaku Pengguna Layanan Hak Tanggungan Terintegrasi secara Elektronik Pasca Terbitnya Permen ATR/BPN Nomor 5 Tahun 2020

Secara normatif, kewenangan PPAT melakukan pengecekan atau pemeriksaan sertipikat tanah tanah disebutkan dalam: Pasal 54 ayat (1) tentang Perkaban No. 1 tahun 2006 menyatakan bahwa "Sebelum pembuatan akta mengenai perbuatan hukum seperti jual beli, tukar menukar, hibah, pemasukan ke dalam perusahaan, pembagian hak bersama, pemberian Hak Guna Bangunan/ Hak Pakai atas tanah Hak Milik, pemberian Hak Tanggungan, dan pemberian kuasa membebankan Hak Tanggungan., PPAT wajib melakukan pemeriksaan kesesuaian/keabsahan sertipikat dan catatan lain pada Kantor Pertanahan setempat dengan menjelaskan maksud dan tujuannya”. Pasal 97 Permen ATR/BPN No. 3 Tahun 1997 tentang Ketentuan Pelaksanaan PP No.24 tahun 1997 tentang Pendaftaran Tanah menyatakan bahwa "Sebelum melaksanakan pembuatan akta mengenai pemindahan atau pembebanan hak atas tanah atau Hak Milik Atas Satuan Rumah Susun, PPAT wajib terlebih dahulu melakukan pemeriksaan pada Kantor Pertanahan mengenai kesesuaian sertipikat hak atas tanah atau Hak Milik Atas Satuan Rumah Susun yang bersangkutan dengan daftar-daftar yang ada di Kantor Pertanahan setempat dengan memperlihatkan sertipikat asli" dan 
"Pemeriksaan sertipikat sebagaimana dimaksud pada ayat (1) dilakukan untuk setiap pembuatan akta oleh PPAT, dengan ketentuan bahwa untuk pembuatan akta pemindahan atau pembebanan hak atas bagian-bagian tanah hak induk dalam rangka pemasaran hasil pengembangan oleh perusahaan real estat, kawasan industri dan pengembangan sejenis cukup dilakukan pemeriksaan sertipikat tanah induk satu kali, kecuali apabila PPAT yang bersangkutan menganggap perlu pemeriksaan sertipikat ulang".

Dalam hal pengecekan sertipikat untuk keperluan pembuatan akta oleh PPAT, harus dilakukan secara elektronik dengan berdasarkan Surat Edaran Kepala Badan Pertanahan Nasional Nomor DI.01.01/361-100/II/2020 tanggal 17 Februari 2020 perihal pengecekan secara elektronik terhadap bidang tanah, PPAT memiliki kewajiban melakukan pengecekan sertipikat tanah secara elektronik sehingga pengecekan sertipikat tanah secara manual ditutup pada tanggal 30 Juli 2020. Pengecekan atau pemeriksaan kesesuaian sertipikat tanah terkait pembebanan hak tanggungan secara elektronik bersifat imperatif bagi PPAT karena apabila PPAT tidak melakukan pengecekan atau pemeriksaan kesesuaian sertipikat tanah elektronik, maka kantor pertanahan setempat akan menolak Hal ini tercantum dalam Pasal 24 Permen ATR/BPN No. 5 Tahun 2020 menyatakan bahwa Kepala Kantor Pertanahan dapat menolak Pelayanan HT-el, antara lain: 1) terdapat sita dan/atau blokir dalam jangka waktu proses Pelayanan HT-el; dan 2) terdapat alasan lain berdasarkan ketentuan peraturan perundang-undangan. Penolakan permohonan Pelayanan HT-el diberitahukan kepada Kreditor melalui Sistem HTel, Domisili Elektronik dan/atau media elektronik lainnya. Pengecekan atau pemeriksaan kesesuaian sertipikat tanah terkait pembebanan hak tanggungan secara elektronik bersifat imperatif bagi PPAT juga sebagai salah satu bentuk tindakan kehati-hatian dalam pelaksanaan jabatan PPAT serta agar tidak terjadi masalah hukum bagi PPAT maupun kreditor/debitor di kemudian hari.

Dalam rangka Persiapan penyelenggaraan Pelayanan HT-el, beberapa hal yang perlu diperhatikan bagi PPAT antara lain:

a. PPAT wajib terdaftar dan terverifikasi pada aplikasi mitra kerja PPAT dengan tata cara sebagai berikut: Pertama, PPAT membuka Aplikasi Mitra Kerja PPAT dan mengisi formulir pendaftaran yang telah tersedia dengan memasukkan data sebagai berikut (Petunjuk Teknis Menteri Agraria Dan Tata Ruang/Kepala Badan Pertanahan Nasional Nomor 2/JUKNIS-400.HR.02/IV/2020 Tahun 2020): NIK adalah Nomor Induk Kependudukan sesuai KTP PPAT; Nama lengkap adalah nama yang tertera pada KTP PPAT tanpa gelar; Nomor Surat Keputusan adalah nomor Surat Keputusan pengangkatan PPAT pertama kali; Tanggal Surat Keputusan adalah tanggal Surat Keputusan pengangkatan PPAT pertama kali; Email dan nomor HP harus aktif untuk menerima kode aktivasi akun PPAT; Membuat nama pengguna dan kata sandi. Nama pengguna dibuat tanpa spasi dan kata sandi dibuat minimal 6 karakter dengan kombinasi huruf 
dan angka; atau Lainnya, apabila diperlukan; Kedua, PPAT akan menerima kode aktivasi untuk masuk ke Aplikasi Mitra Kerja PPAT melalui nomor HP dan email aktif; Ketiga, Selanjutnya PPAT melengkapi biodata yang terdiri dari: Identitas PPAT sesuai KTP; Mengisi wilayah kerja PPAT; Mengunggah file pas foto yang memperlihatkan keseluruhan wajah dengan jelas; Riwayat pendidikan untuk menampilkan gelar yang diinput sesuai tahun lulus(Petunjuk Teknis Menteri Agraria Dan Tata Ruang/Kepala Badan Pertanahan Nasional Nomor 2/JUKNIS-400.HR.02/IV/2020 Tahun 2020); Surat Keputusan Pengangkatan Pertama Kali dan Berita Acara Pengangkatan Sumpah Jabatan PPAT berikut Surat Keputusan pengangkatan kembali/perpanjangan (apabila PPAT yang bersangkutan pernah pindah/berhenti dengan hormat/perpanjangan masa jabatan); Data kantor PPAT meliputi: Foto kantor dan papan nama PPAT; Tanggal mulai aktif;Alamat lengkap;Nomor telepon kantorK Keempat, PPAT melakukan validasi dan bertanggung jawab penuh terhadap data yang diinput; dan Kelima, PPAT berkoordinasi dengan Kantor Pertanahan sesuai wilayah kerja PPAT untuk mendapatkan verifikasi akun mitra.

b. PPAT wajib mengamankan akun sistem elektronik agar tidak dimanfaatkan oleh pihak yang tidak bertanggung jawab. Password wajib mengikuti kaidah sebagai berikut (Petunjuk Teknis Menteri Agraria Dan Tata Ruang/Kepala Badan Pertanahan Nasional Nomor 2/JUKNIS-400.HR.02/IV/2020 Tahun 2020): Password harus menggunakan kombinasi alfanumerik yang sulit ditebak; Password diganti minimal setiap bulan; Tidak berbagi password dengan pengguna lainnya; Segala bentuk penyalahgunaan akun sistem elektronik menjadi tanggung jawab dari pemilik akun.

Dalam rangka Pelaksanaan penyelenggaraan Pelayanan HT-el, beberapa hal yang perlu diperhatikan bagi PPAT antara lain:

a. Pengecekan Sertipikat Hak Atas Tanah (Petunjuk Teknis Menteri Agraria Dan Tata Ruang/Kepala Badan Pertanahan Nasional Nomor 2/JUKNIS400.HR.02/IV/2020 Tahun 2020): PPAT wajib melakukan pengecekan Sertipikat Hak Atas Tanah/Hak Milik Atas Satuan Rumah Susun sebelum pembuatan APHT; Pengecekan Sertipikat Hak Atas Tanah/Hak Milik Atas Satuan Rumah Susun dapat dilakukan oleh PPAT secara manual atau elektronik; Pengecekan Sertipikat Hak Atas Tanah/Hak Milik Atas Satuan Rumah Susun secara elektronik dapat dilakukan apabila data pertanahan sudah dalam bentuk elektronik atau telah diubah dalam bentuk elektronik dan tersedia dalam pangkalan data Kementerian ATR/BPN; Mengingat informasi hasil pengecekan merupakan data yang paling mutakhir, PPAT segera membuat APHT setelah hasil pengecekan diterbitkan oleh Kantor Pertanahan;

b. Pelaporan APHT dilakukan melalui Aplikasi Mitra Kerja PPAT yang diakses melalui https://mitra.atrbpn.go.id; 
c. Pelaporan akta diawali dengan membuat kode akta yang digunakan sebagai salah satu pengenal akta yang terdiri dari 6 (enam) digit alfanumerik berbeda dengan nomor akta;

d. PPAT menginput data akta yang meliputi: Nomor akta; Tanggal akta; Pemegang Hak Tanggungan; Nilai Tanggungan; Objek Hak Tanggungan; Benda lainnya; dan/atau Lainnya, apabila diperlukan;

e. Apabila di dalam APHT terdapat dua nilai yakni nilai pelunasan utang Debitor dan Nilai Tanggungan maka yang diinput adalah Nilai Tanggungan;

f. Nilai Tanggungan adalah nilai dalam mata uang rupiah atau valuta asing tanpa pecahan sen;

g. PPAT mengunggah APHT dan data pendukungnya dengan ukuran resolusi minimal 100 DPI dalam format file PDF, yang meliputi asli dari: NPWP Debitor Perorangan/Badan Hukum; KTP Saksi Pembuatan APHT;KTP Pihak Persetujuan (jika ada), jika tidak ada maka mengunggah surat pernyataan tidak memerlukan persetujuan (Petunjuk Teknis Menteri Agraria Dan Tata Ruang/Kepala Badan Pertanahan Nasional Nomor 2/JUKNIS400.HR.02/IV/2020 Tahun 2020); SPPT PBB tahun berjalan atau SPPT PBB tahun sebelumnya apabila SPPT PBB tahun berjalan belum keluar; Sertipikat Hak Atas Tanah atau HM Sarusun; Surat Kuasa Membebankan Hak Tanggungan apabila dikuasakan; dan Formulir pernyataan dan pertanggung jawaban keabsahan dan kebenaran dokumen;

h. Selanjutnya PPAT mengunduh surat pengantar akta yang berisi nama PPAT, nomor akta dan kode akta. Surat pengantar akta dicetak sebanyak 3 rangkap dan di tandatangani serta di bubuhi stempel PPAT, dengan ketentuan: Satu Lembar menjadi satu kesatuan dengan asli APHT lembar pertama dan lembar kedua untuk disimpan di kantor PPAT; Satu lembar disampaikan kepada Kreditor berikut Salinan APHT dan data pendukung pembuatan APHT; Satu lembar berikut Salinan APHT disampaikan kepada Debitor;

i. PPAT memindai (scan) dan mengunggah (upload) surat pengantar akta yang telah di tandatangani dan di bubuhi stempel yang berfungsi sebagai tanda bukti penyampaian asli APHT dan data pendukungnya secara elektronik kepada Kepala Kantor Pertanahan melalui Aplikasi Mitra Kerja PPAT pada https://mitra.atrbpn.go.id;

j. Apabila ada perbaikan/pencoretan/penggantian/penambahan (renvoi) APHT yang sudah diunggah (upload) dan mempunyai kode akta dapat dilakukan perubahan sebelum APHT didaftarkan dalam Sistem HT-el oleh Kreditor;

k. Selanjutnya APHT yang direnvoi, diunggah (upload) melalui Aplikasi Mitra Kerja PPAT sebagai satu kesatuan dari laporan APHT yang telah mendapatkan kode akta;

1. Untuk Layanan Peralihan Hak Tanggungan berupa akta cessie, akta subrograsi, akta penggabungan/peleburan perseroan/koperasi yang dibuat oleh Notaris 
atau pewarisan yang dibuat oleh pejabat yang berwenang, PPAT membuatkan surat pengantar akta dan melaporkan akta dimaksud disertai surat pengantar akta melalui Aplikasi Mitra Kerja PPAT sebagaimana mekanisme pelaporan APHT;

m. Untuk Kreditor Perorangan, PPAT mengajukan APHT dan memilih Kreditor Perorangan dengan mengisi informasi NIK dan email Kreditor Perorangan yang digunakan dalam Aplikasi Sentuh Tanahku.

\section{KESIMPULAN}

PPAT memiliki peran penting dalam layanan hak tanggungan terintegrasi secara elektronik. Peran PPAT selaku pengguna layanan hak tanggungan terintegrasi secara elektronik pasca terbitnya Permen ATR/BPN Nomor 5 Tahun 2020 adalah mulai dari pembuatan perjanjian kredit, pengecekan sertifikat tanah secara elektronik sebelum membuat Akta Pemberian Hak Tanggungan, Pembuatan Akta Pemberian Hak Tanggungan sampai mengupload Akta Pemberian Hak Tanggungan beserta data pendukungnya kepada Kantor Pertanahan setempat melalui Aplikasi Mitra Kerja PPAT pada https://mitra.atrbpn.go.id. Kemudian PPAT akan menyerahkan salinan minuta Akta Pemberian Hak Tanggungan kepada debitor dan kreditor. Sementara Akta Pemberian Hak Tanggungan yang asli disimpan oleh PPAT.

\section{E. DAFTAR PUSTAKA}

Antari, K. W., Windari, R. A., \& Mangku, D. G. S. (2020). Tinjauan Yuridis Mengenai Antynomy Normen (Konflik Norma) Antara Undang-Undang Nomor 5 Tahun 1960 tentang Peraturan Dasar-Dasar Pokok Agraria Dengan Undang-Undang Nomor 25 Tahun 2007 tentang Penanaman Modal Terkait Jangka Waktu Perolehan Hak Atas Tanah. Jurnal Komunitas Yustisia, 2(2), 8899.

Budjang, C. B. (2018). Jual Beli Tanah Yang Dilakukan Tanpa Akta Ppat. Jurnal Media Hukum Dan Peradilan, 4(1), 89-107.

Dewi, I. G. S., \& Ardani, M. N. (2020). Kebijakan Penjaminan Tanah Melalui Hak Tanggungan di Indonesia (Studi Penjaminan Hak Tanggungan Elektronik di Kabupaten Badung Provinsi Bali). Law, Development \& Justice Review, 3(1), 5769.

Hajati, S., Winarsi, S., Sekarmadji, A., \& Moechthar, O. (2017). Buku Ajar Politik Hukum Pertanahan, Surabaya: Airlangga University Press.

Jayanti, O., \& Darmawan, A. (2018). Pelaksanaan Lelang Tanah Jaminan yang Terikat Hak Tanggungan. Kanun Jurnal Ilmu Hukum, 20(3), 457-472.

Marzuki, P.M. (2011). Penelitian Hukum, Jakarta: Kencana Prenamedia Group.

Permatasari, E., Adjie, H., \& Djanggih, H. (2018). Perlindungan Hukum Kepemilikan Tanah Absentee yang Diperoleh Akibat Pewarisan. Varia Justicia, 14(1), 1-9. 
Riardo, R. (2019). Konversi Hak Atas Tanah Ulayat Kaum Menjadi Hak Milik Melalui Program Pendaftaran Tanah Sistimatis Lengkap di Kota Solok. Soumatera Law Review, 2(2), 193-206.

Taqiyyah, M. A., \& Winanti, A. (2020). Perlindungan Hukum Pemegang Sertifikat Atas Tanah Ganda Berdasarkan Peraturan Pemerintah No. 24 Tahun 1997. Jurnal Justisia: Jurnal Ilmu Hukum, Perundang-undangan dan Pranata Sosial, 5(1), 7793.

Usanti, T.P., \& Bakarbessy, L. (2014). Buku Referensi Hukum Perbankan Hukum Jaminan, Surabaya: Revka Petra Media.

Peraturan:

Permen ATR/BPN Nomor 5 Tahun 2020 tentang Pelayanan Hak Tanggungan Terintegrasi Secara Elektronik.

Petunjuk Teknis Menteri Agraria Dan Tata Ruang/Kepala Badan Pertanahan Nasional Nomor 2/JUKNIS-400.HR.02/IV/2020 Tahun 2020.

Undang-Undang Nomor 4 Tahun 1996 tentang Hak Tanggungan Atas Tanah Beserta Benda-Benda Yang Berkaitan Dengan Tanah 